\title{
“A GENTE SE CUIDA, MAS NÃO CONTA PRA NINGUÉM": UMA ANÁLISE SOBRE AS MASCULINIDADES EM UM FILME PUBLICITÁRIO
}

\section{"NOS CUIDAMOS, PERO NO SE LO DECIMOS A NADIE": UNA ANÁLISIS SOBRE LAS MASCULINIDADES EN UNA PELÍCULA PUBLICITARIA}

\section{“WE CARE, BUT DON'T TELL ANYONE”: AN ANALYSIS OF MASCULINITIES IN AN ADVERTISING MOVIE}

\author{
Guilherme Gomes dos Santos I \\ Ricardo Desidério da Silva 2
}

\section{RESUMO}

A existência de uma essência masculina é socialmente naturalizada, seja excluindo e/ou depreciando tantas outras possibilidades. Neste cenário, empresas se apropriam disso, produzindo e reproduzindo valores por canais midiáticos, adaptados aos seus interesses. A publicidade é uma das ferramentas utilizadas, buscando na cultura as representações para atingir simbolicamente o consumidor. Sendo assim, objetivou-se analisar um filme publicitário de produtos masculinos, promovendo reflexões sobre as masculinidades. Para tal, utilizou-se da pesquisa qualitativa descritiva em formato documental, analisando os dados através da Análise de Conteúdo. Assim, identificou-se a articulação de elementos audiovisuais que correspondem o modelo de masculinidade hegemônica, ao mesmo tempo que amplia a diversidade, ainda reforça estereótipos, notavelmente na busca de estimular o consumo. Por fim, considera-se que as produções publicitárias além de produzir e reproduzir sentidos, também criem possibilidades para ressignificações de valores, tendo a utilização das mesmas como possíveis recursos para atividades em programas de Educação Sexual.

Palavras-chave: Masculinidades. Educação Sexual. Publicidade. Filme publicitário.

\section{RESUMEN}

La existencia de una esencia masculina es socialmente naturalizado, ya sea excluyendo y / o depreciando tantas otras posibilidades. En este escenario, las empresas se apropian, produciendo y reproduciendo valores a través de canales mediáticos, adaptados a sus intereses. La publicidad es una de las herramientas utilizadas, buscando en la cultura las representaciones para llegar simbólicamente al consumidor. Así, el objetivo era analizar una película publicitaria de productos masculinos, promoviendo reflexiones sobre las masculinidades. Para ello,

1 Mestrando em Educação Sexual. Universidade Estadual Paulista “Júlio de Mesquita Filho" - FCLAR, Araraquara, São Paulo, Brasil.

${ }_{2}$ Pós-doutor em Educação Escolar. UNESPAR - Universidade Estadual do Paraná, Apucarana, Paraná, Brasil. 
utilizamos la investigación descriptiva cualitativa en formato documental, analizando los datos a través del Análisis de Contenido. Así, identificamos la articulación de elementos audiovisuales que corresponden al modelo de la masculinidad hegemónica, al mismo tiempo que se amplía la diversidad, todavía refuerza los estereotipos, en la búsqueda de estimular el consumo. Por último, se considera que las producciones publicitarias, además de producir y reproducir sentidos, también crean posibilidades de resignificaciones de los valores, y que pueden ser utilizadas como posibles recursos para las actividades de los programas de Educación Sexual.

PALABRAS-CLAVE: Masculinidades. Educación Sexual. Publicidad, Película publicitaria.

\section{ABSTRACT}

The existence of a masculine essence is socially naturalized, whether excluding and / or disparaging others possibilities. In this scenario, companies take ownership of it, producing and reproducing values through media channels adapted to its interests. The advertising is one of the tools used for it, seeking representations in culture to symbolically reach the consumer. Therefore, the objective was to analyze an advertising film for male products, promoting reflections on masculinities. For this, the documentary qualitative descriptive research was used, analyzing the data through Content Analysis. Thus, the articulation of audiovisual elements that correspond to the hegemonic masculinity model was identified, while expanding diversity still reinforcing stereotypes, seeking to stimulate consumption. Finally, it is considered that advertising productions, in addition to producing and reproducing meanings, also create possibilities for redefinition of values, using them as possible resources for activities in Sexual Education programs.

KEYWORDS: Masculinities. Sex education. Publicity. Advertising film.

$$
* * *
$$

O homem, configurado nas suas relações cotidianas e no seu tempo histórico e social, materializa-se a partir do seu corpo, na qual apenas uma única de suas tantas características será suficiente para construção social de seu ambiente identitário. Essa poderosa característica é sua genitália. Ao descobrir sua identidade na forma de um pênis, esse "ser de muitas possibilidades" ao nascer, torna-se "o menino" que garantirá a solidificação do protótipo de um mundo "tão sonhado". Atribui-se a ele um nome antes mesmo das palavras fazerem sentido, distribuem-se as cores antes que possa distingui-las, seus brinquedos antes de poder brincar, as roupas para além do conforto e os comportamentos antes mesmo de viver. Tudo sendo detalhadamente selecionado, ensinado e imposto.

E é nesta sociedade de controle, de acordo com Foucault (FOUCAULT, 2017), pelas relações de poder, que se constrói o saber sobre o sexo, a sexualidade, articulado por discursos, saberes, constituídos por influências econômicas, jurídicas, religiosas, ideológicas, políticas e do discurso científico. Sendo, uma dinâmica complexa de caráter histórico. Ainda, agregando a reflexão com base em Butler (2003), o entendimento de um corpo sexuado que julga-se ser base para um gênero é um resultante social de toda a dinâmica até então citada. Nada há de 
natural no gênero, configurado por atos reiteradamente colocados e impostos, mas que nunca são incorporados em sua totalidade por serem construções fantasísticas e limitantes, assim, restando a performatividade aos corpos, esforçado-se para representar os modelos.

A diferenciação do sexo está para além da estética do corpo, é um processo regulado por normas forçosamente reiteradas, pois o corpo nunca se conforma completamente com a materialização de tais imposições, construindo o gênero por meios excludentes, criando fronteiras e limitando o ser humano em relação ao seu meio constitutivo (BUTLER, 2000). Um complexo emaranhado de relações sociais globalizadas, explícitas e implícitas, variando em algumas práticas de cultura para cultura, transmitidas de uma geração para outra, estabelecendo relações desiguais de poder e relações de dominação sobre todos que se afastam do modelo instituído de homem.

De acordo com Januário (2016), a compreensão de que a masculinidade não é algo natural e sim uma construção histórica, social e cultural, faz com que possamos pensar que não existe apenas uma, mas várias masculinidades, dinâmicas e cambiantes, caracterizadas como comportamentos e práticas variando dentro de uma mesma pessoa no tempo e no espaço. Logo, é possível pensá-las como um lugar simbólico, produto de um processo de socialização onde são forjados padrões e valores, formações sociais que são alteradas e reiteradas construindo novos sentidos baseados em uma ideologia. Por fim, identifica-se que nossa organização social ainda baseia-se em uma lógica patriarcal, na qual o sexo masculino é a representação de poder, subordinando e inferiorizando o feminino e rivalizando arduamente a soberania entre outros masculinos.

O confronto entre os masculinos pelo lugar de poder é constante. Manter-se nessa posição tem seu preço, referente a isso Bourdieu (2012) afirma que

o privilégio masculino é também uma cilada e encontra sua contrapartida na tensão e contensão permanentes, levadas por vezes ao absurdo, que impõe a todo homem o dever de afirmar, em toda e qualquer circunstância, sua virilidade. [...]. A virilidade, entendida como capacidade reprodutiva, sexual e social, mas também como aptidão ao combate e ao exercício da violência (sobretudo em caso de vingança), é, acima de tudo, uma carga. (p. 64).

Para manter-se nessa posição de poder, o homem, coloca-se vigilante diante de qualquer comportamento que represente fraqueza, geralmente atribuído ao feminino, que contraponha sua virilidade ou de seus semelhantes.

Além da tensão constante, o custo dessa masculinidade prejudica outros âmbitos da vida do homem. A saúde masculina é um dos mais evidentes, muitas vezes negligenciada pelos seus 
iguais, associando seu cuidado preventivo e até remediativo à fraqueza e fragilidade, que são aspectos atribuídos ao feminino. Além disso, tal condição pode ser agravada por variáveis sociais, como por exemplo, classe social e etnia e até pela falta de estratégias políticas e sociais destinadas a essa população (COSTA-JÚNIOR, 2014).

As práticas sociais que configuram as masculinidades, também, são transformadas com o passar do tempo e do contexto onde ocorrem (JANUÁRIO, 2016). Logo, os comportamentos convencionados ao ser masculino modificam-se e se diversificam no tempo e no espaço.

Nessa pluralidade, de acordo com Connell e Messerschmidt (2013), algumas masculinidades se sobrepõem às outras, concebidas no campo do ideal tornando-se referência simbólica constituidora de subjetividades, promovida pelo modelo hegemônico da cultura patriarcal. Logo, as masculinidades hegemônicas se caracterizam e se distinguem de outras pelo seu aspecto normativo com base em um modelo ideologicamente legitimado de ser homem, exigindo que todos os outros o sigam, subordinando os homens em que os atos não representem o idealizado e tudo aquilo que se remete ao feminino. Sendo hegemônico, pois se estrutura por meio da persuasão, das instituições e da cultura. Entretanto, estas masculinidades não são estáticas, envolvem divisão interna e conflito emocional, são transformadas, mas não afetam necessariamente a essência estruturante dos modelos patriarcais, apesar da possibilidade de ocorrer.

A expressão das masculinidades materializa-se nas ações e inevitavelmente no corpo. Formatado pelas forças sociais, customizado através do manejo nutricional, atividades físicas, alterações cirúrgicas, intervenções tecnológicas, roupas, acessórios e cosméticos. Motivado por um sistema capitalista com práticas, normas e valores consumistas, cujo ideal é o corpo jovem, atraente, perfeito. Em seu corpo e através dele o indivíduo expressa sua identidade, muitas vezes, esforçando-se para representar o seu ideal (JANUÁRIO; CASCAIS, 2012). Quando abordamos o capitalismo em suas práticas, normas e valores, e que incidem sobre os processos de subjetivação, compreende-se a necessidade em analisar as diferentes estratégias utilizadas, sendo a Publicidade uma delas.

\section{Publicidade e a Educação Audiovisual da Sexualidade}

A Publicidade é uma importante ferramenta de comunicação, transmitindo conceitos, valores e ideias, de forma racional e/ou emocional, promovendo seu produto e visando o lucro. Além disso, atinge o consumidor com valores simbólicos, representando alguns estereótipos, reforçando padrões comportamentais de práticas sociais dominantes, afetando a conduta dos 
indivíduos (JANUÁRIO; CASCAIS, 2012). A autora e o autor, também, citam que "a Publicidade observa o comportamento dos indivíduos e da sociedade como um todo, e os seus produtores sempre estão atentos ao surgimento de tendências de consumo no âmbito social" (p.141).

Além da publicidade, a educação também se faz por imagens e sons. Nossa sexualidade é influenciada por essas produções, os elementos apresentados são pensados, almejando um fim, produzindo sentidos (SILVA, 2015). Ainda, de acordo com Teixeira e Marques (2016),

com frequência, os anúncios tornam o corpo palco de encenações que apelam ao sexo e à identificação com determinados modelos de masculinidade e feminilidade. As suas representações visuais são cuidadosamente selecionadas recorrendo a estereótipos espelhados em práticas socioculturais. (p. 181).

A miscelânea de elementos representativos da sociedade, entrelaçados com expressões de desejos, sentimentos, valores e ideais, são combinados a produtos ou serviços, atribuindolhes sentidos, inoculando possibilidades práticas e imaginárias que transitam inevitavelmente pelo campo da sexualidade. Nessa trama complexa, estereótipos são reforçados e transformações sociais são incorporadas visando na maioria das vezes atingir o público-alvo. Mesmo que, consideremos um posicionamento crítico e político nessas produções, sabemos que seu fim é vender e estimular o consumo.

A Educação Sexual que poderia promover reflexões críticas, de forma organizada e com base científica, sofre inúmeras repressões. Assim, esse tipo de instrução fica à mercê de outras instituições, reproduzindo, por vezes, as relações preconceituosas e de dominação do sistema vigente, mesmo que involuntariamente. Uma Educação Sexual adequada, segundo Maia e Ribeiro (2011) deveria promover reflexões e questionamentos sobre a sexualidade em seu sentido amplo e nas diversas dimensões, bem como, o seu desenvolvimento histórico-social, os mecanismos de repressão, promovendo um espaço de reflexão crítica para construção dos próprios valores, fomentando o maior respeito, cuidado e atenção com os outros e consigo mesmos, não se direcionando só ao individual, mas ao coletivo.

Como aprendemos vendo e ouvindo, analisar as produções publicitárias pode ser uma excelente possibilidade de identificar as representações sociais do seu tempo e a produção de novos sentidos, neste caso, acerca das masculinidades. Bem como, utilizá-las como recurso para uma Educação Sexual. Logo, possibilitando reflexões sobre uma Educação Audiovisual da Sexualidade como proposta por Silva (2015). 
Vários estudos abordam a questão das masculinidades em produções publicitárias (BALISCEI; CALSA; JORDÃO, 2016; SANTOS; POSTINGUEL, 2016; SANTOS; CARVALHO, 2018; PEREZ; PERUZZO, 2018; RIBEIRO; SILVA; SANTANA; MOTA, 2019; FLORES, 2020). Assim como, identificam estereótipos de masculinidades hegemônicas e algumas transformações fomentadas por mudanças sociais, muitas vezes consideradas como um fim comercial para o consumo e ao mesmo tempo como espaço de representatividade.

Considera-se que filmes publicitários educam, diversas mensagens são transmitidas, vários aspectos podem ser analisados (SILVA, 2015). Tal como, o mesmo material pode dar origem a análises distintas (KRIPKA; SCHELLER; BONOTTO, 2015). Além de produzir diversas informações, o filme e o conhecimento podem servir de recurso para uma Educação Sexual intencional, sistematizada e adequada, como apresentada por Maia e Ribeiro (2011) e Silva (2015). Sendo assim, quais informações emergem ao analisar o conteúdo de um filme publicitário direcionado a população masculina? Dessa forma, este trabalho tem como objetivo analisar um filme publicitário de produtos masculinos, promovendo reflexões sobre as masculinidades.

\section{Método}

Este trabalho caracteriza-se como uma pesquisa qualitativa descritiva de formato documental, onde os dados foram analisados pela a Análise de Conteúdo na modalidade Temática.

A pesquisa qualitativa se propõe a estudar as relações complexas, a partir de um ato subjetivo e social na construção do conhecimento. Os passos da pesquisa precisam ser sistematizados, podendo-se utilizar diversos métodos, desde que, sejam adequados ao objeto de estudo, considerando a influência do pesquisador (GÜNTHER, 2006). Descritiva, pois, pretende-se descrever os elementos do vídeo. Mesmo que, este objeto tenha sido analisado em outros estudos (PITANGA, 2017; POSTINGUEL, 2017), por se tratar de uma pesquisa documental, pode ser reexaminado buscando interpretações novas ou complementares e utilizando métodos e técnicas apropriados para o documento em questão (KRIPKA; SCHELLER; BONOTTO, 2015). 
Objeto de análise

Nesta pesquisa, analisamos o filme de 2016 (30 segundos) da campanha Linha MEN, da empresa O Boticário: "Para você que existe no ogro". Divulgado, dentre outros meios, no site da agência publicitária ALMAPBBDO (2018) que juntamente com a Saigon fez a produção, o filme é apenas um fragmento de toda a publicidade envolvida nessa linha de produtos. A campanha publicitária pode ser vista com mais detalhes no site da empresa: boticariomen.com.br. Optou-se em analisar este filme por ser de uma empresa conhecida nacionalmente, sendo de toda uma linha de produtos estéticos para a população masculina e com mais de um milhão de visualizações no canal do YouTube da empresa (https://www.youtube.com/watch?v=zTXIHkCL9x0).

Procedimento

Fragmentou-se o vídeo em quadros, selecionando alguns para que compusessem as cenas. Definiu-se o critério de escolha pelos quadros que representassem o começo, meio e fim de cada cena que foi distinguida posteriormente pelo cenário. Por fim, o filme e as cenas foram tratados de acordo com a metodologia selecionada para análise dos dados.

Análise dos dados

A metodologia utilizada para análise do vídeo foi a Análise de Conteúdo com base em Bardin (2011), com foco na modalidade temática que é definida como um conjunto de técnicas para análise de comunicações, com procedimentos objetivos e sistemáticos e que seguem uma sequência em torno de três polos: a Pré-análise; a Exploração do material e o Tratamento dos resultados, Inferência e Interpretação. A modalidade temática fundamenta-se em um tema que emerge naturalmente do texto guiada pela fundamentação teórica. Para a condução da Análise de Conteúdo algumas fases são estabelecidas como: organização da análise; codificação; categorização; tratamento dos resultados, inferência e a interpretação dos resultados (URQUIZA; MARQUES, 2016).

A fase de organização acontece na Pré-Análise, etapa mais intuitiva, de sistematização das ideias em um plano de análise. A Exploração do material, etapa mais longa, onde o dado se constrói no contato repetitivo e exaustivo com o material, codificando e categorizando. $\mathrm{O}$ Tratamento dos resultados e a Interpretação configuram-se por meio da inferência, 
construída através da trama consistente, entre as questões da pesquisa e a fundamentação teórica (SILVA, 2015, grifo nosso).

\section{Resultados e Discussões}

Pré-Análise

Foram identificados diversos elementos que faziam um entrelaçamento entre texto, imagens e áudios (falado e melodia). Vários aspectos são perceptíveis sem profundas análises, por exemplo, os diversos biótipos escolhidos para os personagens, seus comportamentos e a própria letra da música, junto à forma como é cantada, representam modelos de masculinidades hegemônicas (CONNELL; MESSERSCHMIDT, 2013; JANUÁRIO, 2016) e seus desdobramentos.

Visando obter o maior número de aspectos possíveis, abriu-se o foco para diversos elementos, codificando e categorizando-os de forma abrangente, realizando inferências específicas e gerais.

\section{Exploração do Material}

Antes de realizar a Codificação e a Categorização, necessita-se preparar os sintagmas, entendidos como os produtos gerados pela preparação (ex: edições e recortes) do material. Primeiro, codifica-se, para depois categorizar. Codificar é transformar os dados brutos, em uma representação do conteúdo e Categorizar, configura-se em, organizar as informações codificadas, simplificando e tornando visíveis aspectos que não estavam tão evidentes (URQUIZA; MARQUES, 2016).

Para facilitar a análise, dividiu-se o vídeo em quadros, nos quais alguns foram selecionados por representar início, meio ou fim de cada cena. O texto do áudio está apresentado junto a sua respectiva cena, como segue abaixo.

Cena 1 - Nada me deixa mais furioso, do que ficar com o rosto oleoso. (texto 1)

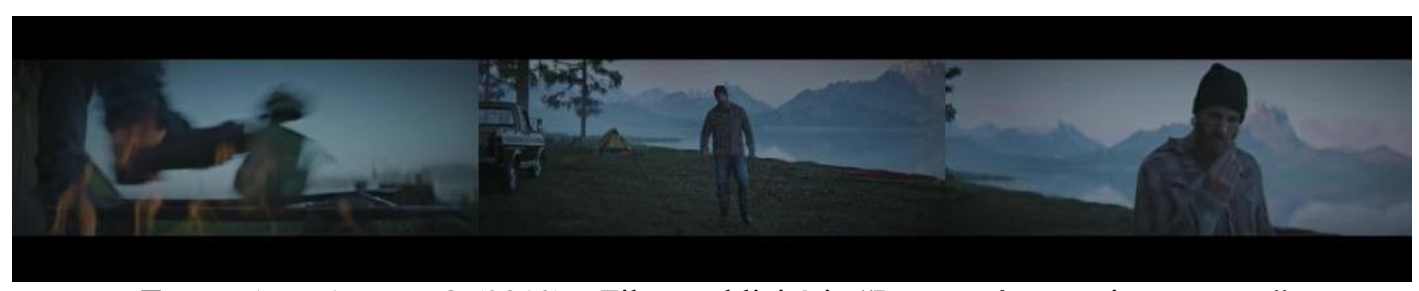

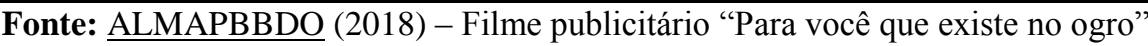


Cena 2 - Pra isso eu tenho um macete, que eu chamo de sabonete. (texto 2)

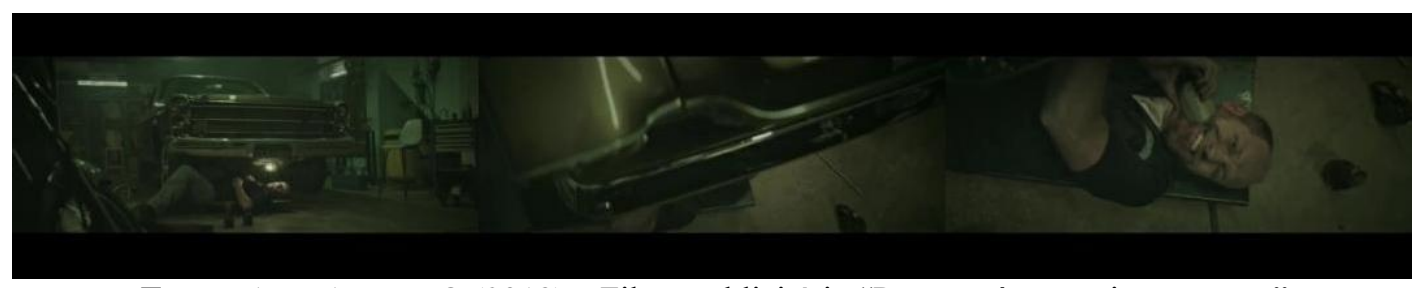

Fonte: ALMAPBBDO (2018) - Filme publicitário "Para você que existe no ogro"

Cena 3 - Perfumaria, desodorante, só um pouquinho de hidratante. (texto 3)

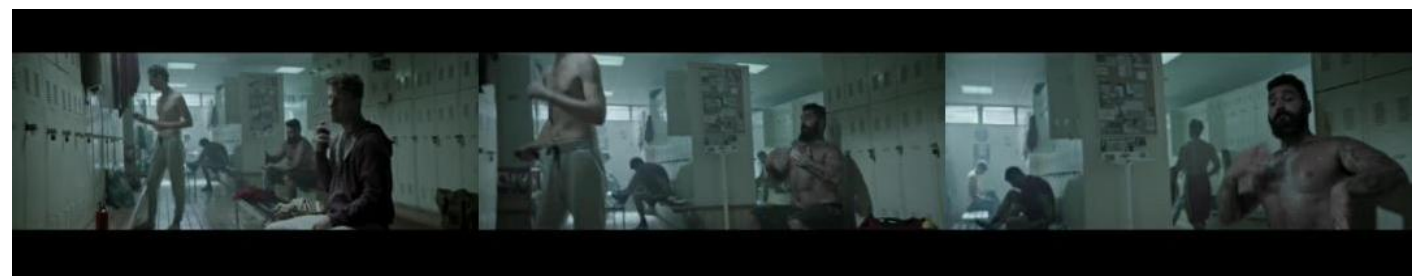

Fonte: ALMAPBBDO (2018) - Filme publicitário "Para você que existe no ogro"

Cena 4 - Pós-barba e shower gel, pra você conquistar a sua guel. (texto 4)

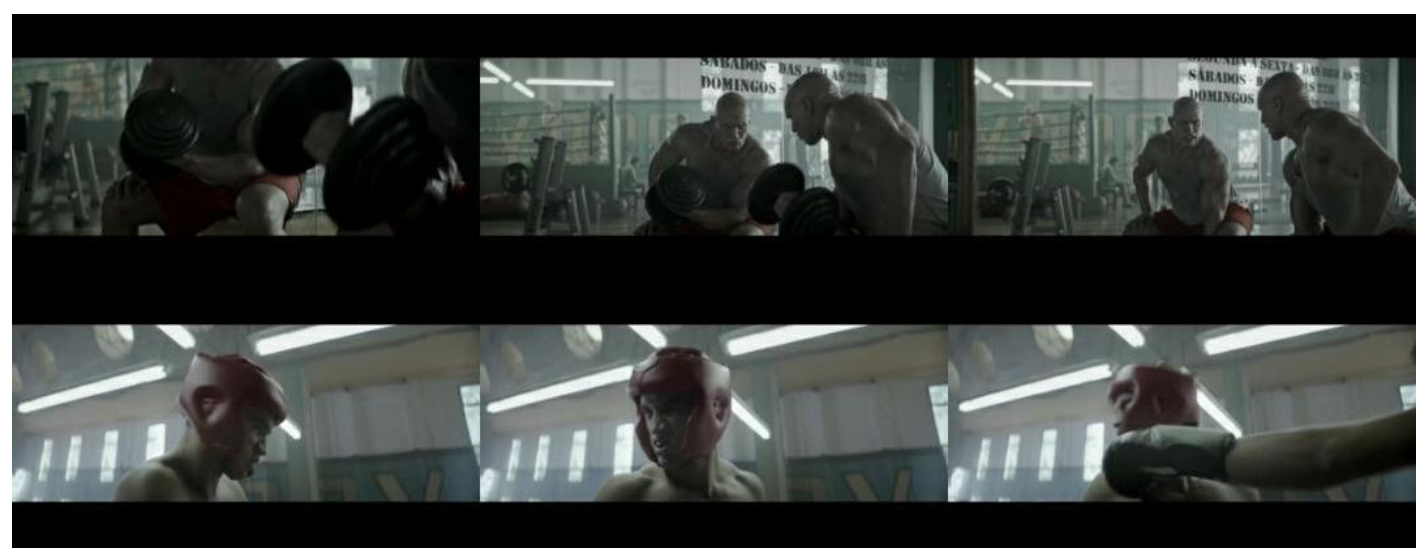

Fonte: ALMAPBBDO (2018) - Filme publicitário "Para você que existe no ogro"

Expressão e emissão de um “Ham!” (Lutador). Como se, não tivesse entendido algo, provavelmente em relação ao erro da pronuncia ("girl” X "guel”) do personagem anterior, porém, presentes no mesmo cenário (mais amplo). (texto 4)

Cena 5 - Se quer um conselho, eu te dou seis em um, mas se me perguntar, eu não uso nenhum. (texto 5)

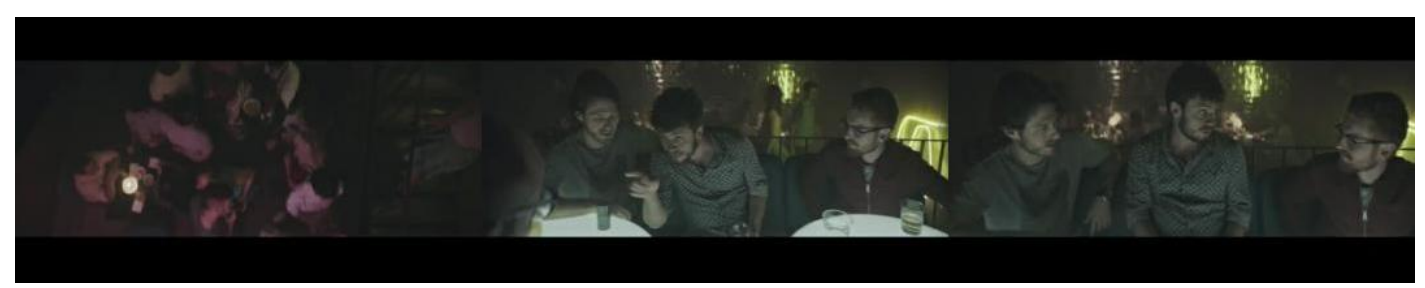

Fonte: ALMAPBBDO (2018) - Filme publicitário "Para você que existe no ogro" 
Cena 6 - A gente se cuida, mas não conta pra ninguém. Ainda bem que tem Boticário Men, Boticário Men! Narrado pelo locutor em off: "Linha Men do O Boticário, para você que existe no ogro." (texto 6).

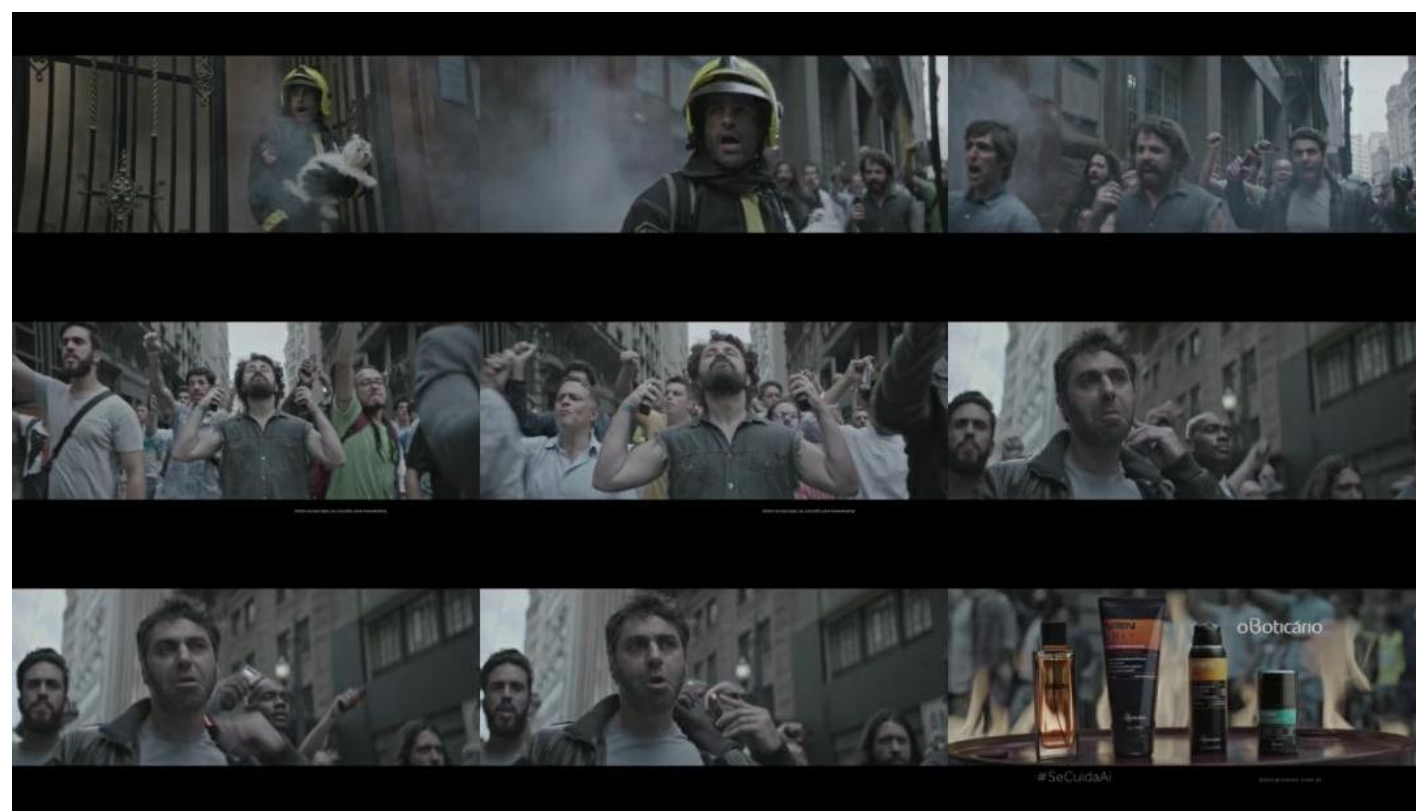

Fonte: ALMAPBBDO (2018) - Filme publicitário "Para você que existe no ogro"

Com base nos dados codificados e categorizados, entrelaçados com a fundamentação teórica, originaram-se quatro temáticas: Masculinidade e Consumo; Masculinidades e Imagens; Masculinidades e Áudio/Texto; e Elementos Pró-Masculinidades.

\section{Masculinidades e Consumo}

Inegavelmente somos produto e produtores de práticas de consumo. Caracterizadas por excessos de experiências efêmeras, transitando pelas necessidades afetivas na busca de um ideal de si, construindo subjetividades, almejando um constante bem-estar individual com base no "ter”, configurando conjunturas de sociabilidades (JANUÁRIO, 2016).

Cada produção midiática tem seus objetivos e para atingi-los os elementos apresentados são pensados, escolhidos e organizados (SILVA, 2015). Sabe-se que o público-alvo do filme publicitário, em análise é o masculino, mas não qualquer um e sim o "ogro", um modelo simbólico representativo das masculinidades hegemônicas patriarcais.

Os meios de comunicação, segundo Januário e Cascais (2012),

"[...] padronizam modelos de masculinidades plurais e conflituosas na sua própria representação mediática, a qual pode trazer um certo 'conforto social', mas que por ora caracteriza estereótipos por vezes preconceituosos do que realmente constituem as masculinidades plurais." (p. 141). 
A busca mercadológica para atingir o público masculino no campo da saúde e/ou estética, evidencia-se na produção simbólica de uma expressão subjetiva denominada "metrossexual", termo geralmente atribuído para aqueles que buscam e se preocupam com o cuidado estético de si (SILVA, 2006). No entanto, esse recorte identitário não resume as masculinidades. Infere-se que, o filme publicitário "Para você que existe no ogro", busca atingir a população masculina que não se identifica com o "metrossexual", muitas vezes associada a homens de orientação homossexual. A relação de dominação masculina acontece, também, com aqueles homens que apresentam características convencionadas ao feminino, por exemplo, cuidados estéticos, logo sendo subjugados pelas masculinidades patriarcais, defensoras da "virilidade" masculina (BOURDIEU, 2012).

Em uma sociedade capitalista onde se vive para consumir o lucro é a meta, o objetivo e o valor central das produções mercadológicas. Para tal fim, inúmeras estratégias são adotadas, sendo as publicitárias uma delas. Na publicidade cada elemento é pensado, organizado e planejado e os envolvidos estão atentos o tempo todo analisando os comportamentos da população, articulando, explicita e implicitamente, produzindo novos sentidos associando aos seus produtos e serviços (JANUÁRIO; CASCAIS, 2012). Essa articulação dos elementos publicitários em relação as masculinidade para o consumo também são identificados nos estudos de Perez e Peruzzo (2018) e Flores (2020). De certa forma, a produção parte da fragilidade identitária masculina hegemônica, a dificuldade de performar o modelo em sua totalidade. Até mesmo os biótipos e vestimentas dos personagens, os cenários, as cores, o áudio e o texto, tudo pensado com base nessa fragilidade, não se remetendo ao feminino, mas simbolizando um cuidado diferente, exclusivo do "ogro".

Masculinidades em Imagens

As imagens ensinam e acabam tornando-se, também, variáveis a serem analisadas na construção de nossa sexualidade (SILVA, 2015). Na publicidade, "as suas representações visuais são cuidadosamente selecionadas recorrendo a estereótipos espelhados em práticas socioculturais.” (TEIXEIRA; MARQUES, 2016, p. 181).

Para atingir um público-alvo, os produtores adotaram diversas estratégias imagéticas. Uma delas se evidenciou pelos personagens representados diversificando os biótipos, vestimentas, comportamentos, representações ocupacionais e de lazer, mas excluindo quaisquer características estereotipadas à homossexualidade ou algo que seja relacionado ao feminino. Tal consideração também vale para os cenários. 
O esforço para demonstrar a virilidade masculina é notável: no modo de falar; de andar; a expressão facial que nomeamos como "de poucos amigos", agressiva, intimidadora e quando não, atravessada pelo humor; o cantar; a referência à conquista do sexo oposto; a vestimenta; a própria escolha de veículos antigos clássicos convencionados ao masculino; os comportamentos (ex: chutar uma chaleira, por sentir raiva de algo (Cena 1) ou ascender um fósforo na barba (Cena 6)); até mesmo a apresentação e uso dos produtos (ex: o hidratante sendo aplicado de forma "xucra" na Cena 3); entre outros.

O ambiente doméstico é comumente colocado como o espaço feminino. Nesse aspecto, Bourdieu (2012) discorre que os homens são raramente associados ao ambiente doméstico,

[...] entre os lugares destinados sobretudo aos homens, como os bares e os clubes do universo anglo-saxão, que, com seus couros, seus móveis pesados, angulosos e de cor escura, remetem a uma imagem de dureza e de rudeza viril, e os espaços ditos "femininos", cujas cores suaves, bibelôs e rendas ou fitas falam de fragilidade e de frivolidade. (p. 72)

Apesar de, o autor remeter-se a uma realidade cultural diferente à do Brasil, muitas das práticas culturais e características são percebidas em nossa realidade. Nenhum cenário do filme representa o âmbito doméstico. Os objetos, estruturas, móveis e automóveis tem aparência antiga, com algum grau de uso e a maioria em cores escuras. Assim, percebe-se o manejo voluntário dos detalhes para corresponder o tipo de masculinidade em questão evidenciando o caráter performático do gênero como compreendido por Butler (2003). Mesmo que apresentassem muitas outras diversas representações de masculinidades não contemplaria todas as possibilidades, pois o modelo hegemônico nunca é incorporado em sua totalidade, apesar dos corpos performarem em seus atos.

Esse esforço publicitário para alcançar grupos específicos de masculinidades manejando os elementos visuais e ou auditivos de acordo com as representações correspondentes, é identificada em outros estudos como, por exemplo, de Baliscei, Calsa, Jordão (2016) e Ribeiro, Santana e Mota (2019),

\section{Masculinidades e Áudio/Texto}

Além das imagens temos aspectos como os sons, falas e textos que também são importantes (SILVA, 2015). "Enquanto mensagem, além da compreensão do enunciado, o texto publicitário exige a sedução do receptor: os elementos verbais e para verbais dispostos num anúncio são trabalhados segundo estratégias persuasivas.” (JANUÁRIO, 2016, p.209). 
A produção auditiva do filme acompanha a mesma coerência que a imagética, em relação ao tipo de masculinidade alvo. Assim, segue a exposição dos textos falados e as inferências em negrito:

Cena 1. "Nada me deixa mais furioso (a expressão de um sentimento que se remete ao masculino, a virilidade (BOURDIEU, 2012), tornando quem se encontra nesse estado, inclinado a uma ação.), do que ficar com o rosto oleoso. (Em sequência a condição do motivo da fúria.).

Cena 2. Pra isso eu tenho um macete, que eu chamo de sabonete. (Apresentam-se a alternativa para aquela condição desagradável que foi "masculinizada", introduzindo o produto, dando início a construção simbólica de alternativas que não abale a frágil masculinidade, mas, ao mesmo tempo, que se torne uma preocupação masculina.).

Cena 3. Perfumaria, desodorante, só um pouquinho de hidratante. (inclusão de outros produtos.).

Cena 4. Pós-barba e shower gel, pra você conquistar a sua guel. (Além de introduzir novos produtos insere uma nova condição para seu uso, porém, com um processo diferente do anterior. Antes era para eliminar uma condição aversiva, nesta situação, se constrói uma relação para conseguir algo que deseja, neste caso algo a conquista afetivo-sexual do sexo oposto.

Esses tipos de manejos são coerentes com as estratégias de “operantes de consumo", utilizadas para intervir sobre o comportamento do consumidor (NALINI; CARDOSO; CUNHA, 2013)). A emissão de um “Ham! ”seguido de uma forte expressão (Lutador).(O filme tem um tom cômico. O discurso publicitário se pluralizou para além do convencer, busca de forma criativa, por meio das emoções, atingir seu público-alvo (JANUÁRIO, 2016).).

Cena 5. Se quer um conselho, eu te dou seis em um, mas se me perguntar, eu não uso nenhum. (Aqui se percebe explicitamente a fragilidade masculina, através de um trocadilho com o nome do produto, diante do "cuidar de si", geralmente convencionado ao feminino).

Cena 6. A gente se cuida, mas não conta pra ninguém. Ainda bem que tem Boticário Men, Boticário Men!(cantada por todos os personagens da cena).(Este trecho é cantado por todos como um hino, podendo ser comparado aos hinos nos estádios de futebol, ambiente ainda tipicamente masculino. Ao fim, o discurso persuasivo formaliza a linha de produtos, como a alternativa, para o conflito entre Cuidado de si X Masculinidade.).

Narrado pelo locutor em off: "Linha Men do O Boticário, para você que existe no ogro. ”(Ao fundo, uma locução reforça a ideia anterior.).

Texto escrito: 
$\mathrm{Na}$ Cena 6, aparecem textos escritos. No meio da cena aparece, "Visite nossas lojas ou consulte uma revendedora" (associando a produção à empresa, como foco na venda), durante dois segundos. No fim da cena aparece várias informações textuais ao mesmo tempo: "\#SeCuidaAí” (estimulando o cuidado de sim, mas em uma linguagem popular, utilizada nas redes sociais e que não se remeta ao feminino), o nome da empresa "oBoticário" (relacionando a empresa) e o site da linha de produtos "boticariomen.com.br" (um local virtual de compra onde também, a produção publicitária visa persuadir esse público).

\section{Elementos Pró-Masculinidades}

O filme apresenta uma grande diversidade de constituições biotípicas masculinas, não reduzindo a um único ideal de corpo. Mesmo entendido que, a produção publicitária visa o consumo e o lucro, considera-se benéfico o estímulo para o cuidado com o corpo, transitando por questões de higiene no próprio cotidiano.

Um exemplo, referente à necessidade desse tipo de cuidado, está relacionado aos fatores de risco do câncer de pênis. O Brasil é um dos países com maiores incidências do mundo, a higiene precária é o principal fator de risco, agravada pela resistência dos homens na busca de assistência médica, seja para prevenção ou tratamento dessa condição ou outras doenças. (COSTA; RODRIGUES; LAURIVANIA; SILVA; BRANDÃO; MEDEIROS, 2013).

A escassez de estratégias eficientes dos sistemas de saúde, em estimular a população masculina para o autocuidado, reflete no aumento de mortalidade e menor expectativa de vida para os homens (COSTA-JÚNIOR, 2014). Com isso, outro elemento Pró-Masculinidades, seriam as próprias estratégias publicitárias de persuasão, que poderiam ser aproveitadas para o cujo fim não fosse o lucro, mas a promoção de saúde dessa população.

\section{Considerações Finais}

Este trabalho teve como objetivo analisar um filme publicitário de produtos masculinos, promovendo reflexões sobre as masculinidades. Logo, com base nos dados identificados e o referencial teórico adotado, fica evidente que o ser masculino é uma imposição construída socialmente em que os corpos estão constantemente performando e sendo subjugados quando não o fazem como o modelo. Dentro desta dinâmica performática as estratégias publicitárias são construídas, associando seus produtos na diversidade de representações dentro da masculinidade em questão, compondo masculinidades, mas ainda em seu aspecto hegemônico. 
São notáveis as inúmeras possibilidades de performar-se como homem e também suas fragilidades que são identificadas pela publicidade, analisando e articulando em representações, simbolismos, através de imagens, sons e palavras, visando atingir seus objetivos, estimulando o consumo e aumentando os lucros. No entanto, em segundo plano ou involuntariamente, também promovem elementos que podem ser benéficos à sociedade, e com uma análise mais profunda, podem-se extrair estratégias para promoção desses benefícios.

Como encontrado em outros estudos que analisam trabalhos publicitários relacionados as masculinidades, identificou-se diversos estereótipos de uma masculinidade hegemônica, mas também apresentou outras representações performáticas. O modelo "ogro" representativo da virilidade foi expresso em diferentes facetas, talvez concebida pela estratégia com via da identificação dos corpos que performam e se dedicam a seguir este modelo.

Considera-se que um filme publicitário, mesmo de curta duração, possui inúmeros elementos que permitem diversas análises, não se esgotando em um só estudo, mas proporcionando reflexões, sobre como são percebidas e reproduzidas as masculinidades. Sendo que, o reconhecimento de produções midiáticas, como proposto por Silva (2015), sobre uma educação audiovisual da sexualidade, revela ser uma ferramenta interessante para a Educação Sexual com grande potencial para reflexões críticas.

\section{Referências}

ALMAPBBDO. Nova campanha de O Boticário mostra como os homens se cuidam: novos produtos para facilitar a rotina de cuidados dos homens. Disponível em: https://www.almapbbdo.com.br/pt/trabalhos/nova-campanha-de-o-boticario-mostra-como-oshomens-se-cuidam+85. Acesso em 12 out. 2018.

BALISCEI, João Paulo; CALSA, Geiva Carolina; JORDÃO, Vitor Hugo. O Homem-Malbec e a construção visual da masculinidade. Textura, v. 18 n. 37, p. 69-89, mai/ago. 2016.

BARDIN, Laurence. Análise de Conteúdo. Lisboa: Edições 70, 2011, 280 p.

BOURDIEU, Pierre. A Dominação Masculina. $11^{\text {a }}$ ed. Rio de Janeiro: Bertrand Brasil, 2012, $160 \mathrm{p}$. 
BUTLER, Judith. Corpos que pesam: sobre os limites discursivos do 'sexo'. In: LOURO, Guacira Lopes (org.). O corpo educado: pedagogias da sexualidade. Belo Horizonte: Autêntica, 2000. p. 151-172.

BUTLER, Judith. Problemas de Gênero: feminismo e subversão da identidade. Rio de Janeiro: Civilização Brasileira, 2003, 237 p.

CONNELL, Raewyn W.; MESSERSCHMIDT, James W. Masculinidade hegemônica: repensando o conceito. Revista Estudos Feministas, Florianópolis, v. 21, n. 1, p. 241-282, jan./abr. 2013.

COSTA, Syvoney; RODRIGUES, Rosiane; LAURIVANIA, Barbosa; SILVA, Jaílson Oliveira; BRANDÃO, José Odinilson de Caldas.; MEDEIROS, Caroline Sanuzi Quirino. Câncer de pênis: epidemiologia e estratégias de prevenção. Cadernos de Graduação - Ciências Biológicas e da Saúde Facipe: Recife, v. 1, n.2, p. 23-33. nov. 2013.

COSTA-JÚNIOR, Florêncio Mariano. Masculinidades, classe social e etnia: discutindo as desigualdades em saúde no cenário brasileiro. Psicologia. PT. 2014. Disponível em: http://www.psicologia.pt/artigos/textos/A0790.pdf. Acesso em 14 out. 2018.

FLORES, Ana Paula. A publicidade da Johnnie Walker e a construção de identidades masculinas. Fórum Linguístico, Florianópolis, v.17, n.1, p.4517-4539, jan./mar. 2020.

FOUCAULT, Michel. História da sexualidade: a vontade de saber. 6a ed. Rio de Janeiro/São Paulo: Paz e Terra, 2017, 175 p.

GÜNTHER, Hartmut. Pesquisa Qualitativa Vesus Pesquisa Quantitativa: Esta É a Questão? Psicologia: teoria e pesquisa. Brasília, v. 22 n. 2, p. 201-210, mai./ago. 2006.

JANUÁRIO, Soraya Barreto. Masculinidades em (re)construção: Gênero, Corpo e Publicidade. Covilhã: Labcom. Ifp, 2016. 408 p.

JANUÁRIO, Soraia Bernardino Barreto; CASCAIS, Antônio. O corpo masculino na publicidade: Uma discussão contemporânea. Revista Comunicação e Sociedade, v. 21, p. 135148. 2012. 
KRIPKA, Rosana Maria L; SCHELLER, Morgana; BONOTTO, Danusa de Lara. Pesquisa Documental: considerações sobre conceitos e características na Pesquisa Qualitativa. Investigação Qualitativa em Educação, v.2, p. 243-247, 2015. Disponível em https://proceedings.ciaiq.org/index.php/ciaiq2015/article/view/252/248. Acesso em 13 mar. 2020.

MAIA, Ana Cláudia Bortolozzi; RIBEIRO, Paulo Rennes Marcal. Educação sexual: princípios para ação. Doxa. Revista Paulista de Psicologia e Educação, v. 15, n. 1, p. 41-51, 2011.

NALINI, Lauro Eugênio Guimarães.; CARDOSO, Michel de Melo.; CUNHA, Sinthia Rodrigues. Comportamento do consumidor: uma introdução ao Behavioral Perspective Model (BPM). Fragmentos de Cultura, Goiânia, v. 23, n. 4, p. 489-505, out./dez. 2013.

PEREZ, Clotilde; PERUZZO, André Luiz Silva. Masculinidades em anúncio: a publicidade enquanto tecnologia de gênero. Tríade, Sorocaba, SP, v. 6, n. 13, p. 69-84, dez. 2018.

PITANGA, Carolina Vasconcelos. Produções discursivas em campanhas publicitárias: gênero e interseccionalidades. 2017. 193 f. Tese (Doutorado)- Curso de Ciências Sociais, Universidade Federal do Maranhão, São Luís, 2017.

POSTINGUEL, Danilo. Ogro com cheiro de cabra macho: a permanência imagética de uma masculinidade na comunicação publicitária. Cultura Midiática. Paraíba, n. 19, p.152-168. Jul./dez. 2017.

RIBEIRO, Bruno César Peralta; SILVA, Gabriela Vieira; SANTANA, Monalisa Santos; MOTA, Romilda Costa. Discutindo estereótipos de gênero. Análise das representações das novas masculinidades em campanhas publicitárias. CPMark - Caderno Profissional de Marketing, v.7, n.1, 2019.

SANTOS, Felipe Bordinhão; POSTINGUEL, Danilo. Masculino Plural e Comunicação Publicitária: A Dinâmica Atualização da Masculinidade Hegemônica. Novos Olhares, v. 5, n. 1, p. 79-89, jul. 2016. 
SANTOS, Sofia José; CARVALHO, Alexandre de Sousa. Violência cultural, masculinidades e publicidade: a campanha “É de homem!" da L’Oréal em Portugal. ORGANICOM. n. 28, p. 206-222, 2018.

SILVA, Ricardo Desidério. Educação Audiovisual da Sexualidade: olhares a partir do Kit Anti-Homofobia. 2015. 144 f. Tese (Doutorado)- Educação Escolar, Universidade Estadual Paulista "Júlio de Mesquita Filho" (Faculdade de Ciências e Letras), Araraquara, 2015.

SILVA, Sérgio Gomes. A crise da Masculinidade: Uma Crítica à Identidade de Gênero e à Literatura Masculinista. Psicologia Ciência e Profissão, v. 26, n. 1, p. 118-131, 2006.

TEIXEIRA, Filomena; MARQUES, Fernando Moreira. O corpo em cena: género e sexo na (publi)cidade. In: DESIDÉRIO, Ricardo. Sexualidade, educação e mídias: novos olhares, novas práticas. Londrina: Eduel, 2016. p. 181-196.

URQUIZA, Marconi de Allburquereque; MARQUES, Denilson Bezerra. Análise de conteúdo em termos de Bardin aplicada à comunicação corporativa sob o signo de uma abordagem teórico-empírica. Entretextos, Londrina, v. 16, n. 1, p. 115-144, jan./jun. 2016. 